\title{
Optical Properties of Erbium Zinc Tellurite Glass System
}

\author{
Sidek Hj. Abdul Aziz, ${ }^{1}$ R. El-Mallawany, ${ }^{2}$ Siti Shawaliza Badaron, ${ }^{1}$ \\ Halimah Mohamed Kamari, ${ }^{1}$ and Khamirul Amin Matori ${ }^{1}$ \\ ${ }^{1}$ Glass, Ceramic and Composite Research Group, Department of Physics, Faculty of Science, Universiti Putra Malaysia, \\ 43400 Serdang, Selangor, Malaysia \\ ${ }^{2}$ Physics Department, Faculty of Science, Menofia University, Shibin Al Kawm, Egypt
}

Correspondence should be addressed to Sidek Hj. Abdul Aziz; sidek@upm.edu.my

Received 16 October 2014; Revised 8 December 2014; Accepted 9 December 2014

Academic Editor: Jun Liu

Copyright (C) 2015 Sidek Hj. Abdul Aziz et al. This is an open access article distributed under the Creative Commons Attribution License, which permits unrestricted use, distribution, and reproduction in any medium, provided the original work is properly cited.

$\mathrm{Er}^{3+}$-doped tellurite glasses with molar compositions of $x \mathrm{Er}_{2} \mathrm{O}_{3}-20 \mathrm{ZnO}-(80-x) \mathrm{TeO}_{2}(x=0,1,2,3$, and 4 mole\%) (EZT) have been successfully synthesized by the melt-quenching method. Density and molar volume have been measured. UV-VIS absorption spectra in the wavelength range of $400-800 \mathrm{~nm}$ at room temperature has been measured. The band gap for every composition has been calculated. Photoluminescence spectroscopy in the wavelength range of 400-650 $\mathrm{nm}$ and at room temperature has been evaluated.

\section{Introduction}

Recently, tellurite glass has been used for lasing materials and amorphous silicon solar cells $[1,2]$. The properties of the host material are very important to study before being doped with any rare-earth elements. Some of the fundamental aspects of tellurite glasses such as glass structure, physical, thermal, optical, and other spectroscopy properties have been extensively studied [3-16]. Most of the research that is emphasized particularly on tellurite glass doped with rare-earth element has been carried out. Erbium doped tellurite glasses considerable literature has recently emerged concerning the structure, optical, mechanical, thermal, and electrical properties. The optical properties of glasses have been an important topic of continuing interest. For instance, the excellent optical properties of $\mathrm{Er}^{3+}$-doped gallium tellurite glasses that promising laser and amplifier material was studied [17].

The aim of this study is to synthesis and characterization of the $\mathrm{Er}_{2} \mathrm{O}_{3}-\mathrm{ZnO}-\mathrm{TeO}_{2}$ (EZT) glass system. Density, molar volume of glass, X-ray diffraction (XRD), and the chemical composition of the glass samples will be measured. Absorption and emission spectra through UV-Vis-NIR and photoluminescence spectroscopy, respectively, will be measured.

\section{Experimental Work}

Glass samples were prepared by using tellurium dioxide (purity $\geq 99 \%$ ), zinc oxide, $\mathrm{ZnO}$ (purity $>97 \%$ ), and erbium (III) oxide (purity 99.9\%). The powder chemicals were weighed using an electronic digital weighting machine with an error of $\pm 0.01 \mathrm{~g}$. Each batch was then melted at 700 $900^{\circ} \mathrm{C}$ in the melting furnace. The melt was held at this temperature for 30 minutes until a bubble-free liquid was formed. The melt was stirred to achieve desirable homogeneity. The homogeneous melt was quenched by pouring it onto a preheated stainless steel mold to avoid excess thermal shocks. The glasses were annealed for 1 hour at $10^{\circ} \mathrm{C}$ higher than the glass transition temperature to release the mechanical strains. The glass samples with molar compositions of $x \mathrm{Er}_{2} \mathrm{O}_{3}$ $20 \mathrm{ZnO}-(80-x) \mathrm{Te}(x=0,1,2,3$, and 4 mole\%) (known as EZT) were successfully synthesized by the melt-quenching method. The samples were cut into pieces having appropriate dimensions for absorption and emission optical and density measurement [18].

The amorphous nature of each glass sample was confirmed by using X-ray diffraction (XRD) and the chemical composition of the glass samples was analyzed by using energy dispersive X-ray fluorescence (EDXRF). The bulk 
TABle 1: Composition (mol\%), molar mass, molar volume, and density of $x \mathrm{Er}_{2} \mathrm{O}_{3}-20 \mathrm{ZnO}-(80-x) \mathrm{TeO}_{2}$ glasses.

\begin{tabular}{|c|c|c|c|c|c|c|}
\hline $\begin{array}{l}x \mathrm{Er}_{2} \mathrm{O}_{3} \\
(\mathrm{~mol} \%)\end{array}$ & $\begin{array}{c}\mathrm{ZnO} \\
(\mathrm{mol} \%)\end{array}$ & $\begin{array}{c}(80-x) \\
\mathrm{TeO}_{2} \\
(\mathrm{~mol} \%)\end{array}$ & $\begin{array}{c}\text { Molar mass } \\
(\mathrm{g} / \mathrm{mole})\end{array}$ & $\begin{array}{l}\text { Molar volume } \\
\left(\mathrm{cm}^{3} / \mathrm{mole}\right)\end{array}$ & $\begin{array}{l}\text { Density } \\
\left(\mathrm{g} / \mathrm{cm}^{3}\right)\end{array}$ & $\begin{array}{c}\text { Optical band gap } \\
E_{\text {opt }}(\mathrm{eV})\end{array}$ \\
\hline 0 & 20 & 80 & 139.62 & 33.08 & 4.22 & 3.04 \\
\hline 1 & 20 & 79 & 141.68 & 33.05 & 4.28 & 3.10 \\
\hline 2 & 20 & 78 & 143.36 & 32.86 & 4.36 & 3.12 \\
\hline 3 & 20 & 77 & 144.28 & 32.75 & 4.44 & 3.13 \\
\hline 4 & 20 & 76 & 146.26 & 32.66 & 4.47 & 3.14 \\
\hline
\end{tabular}

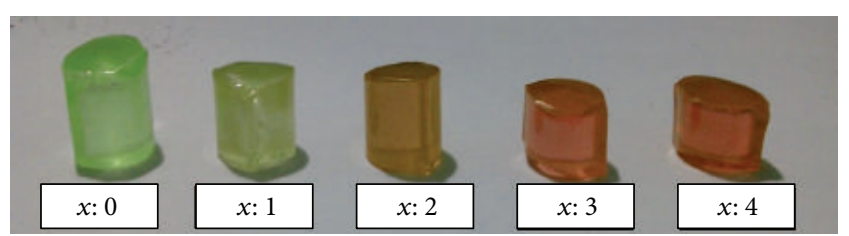

Figure 1: The erbium doped $x \mathrm{Er}_{2} \mathrm{O}_{3}-20 \mathrm{ZnO}-(80-x) \mathrm{TeO}_{2}(x=0,1$, 2,3 , and $4 \mathrm{~mol} \%$ ) (EZT) glass samples.

density of glass samples was measured using the Archimedes principle at room temperature and the molar volumes were estimated quantitatively. All the glass samples were measured using XRD measurement system in the powder form. The EDX analysis was performed by using the fluorescence $\mathrm{X}$-ray spectrometer EDX-720/800HS/900HS/. UV-Vis spectrophotometer (Lambda 35, Perkin Elmer) system has been used with sample thickness 1.88 to $2.04 \mathrm{~mm}$ have been used.

\section{Results and Discussion}

Five of EZT glasses have been successfully prepared where all glass samples are transparent, bubble-free, and homogeneous. The glass color changes to be more growing pink with increasing of erbium content as shown in Figure 1. Figure 2 represents the XRD measurement EZT glass. Figure 2 shows a broad halo characteristic, which confirms the amorphous structure.

Figure 3 shows that the density of EZT glass is increased with the addition of $\mathrm{Er}_{2} \mathrm{O}_{3}$ content. The increasing in density of the glasses is due to the heavier erbium atomic mass as compared to the other element in the glass samples. The atomic mass of erbium is 167.259 which is heavier compared to tellurium (127.60) and zinc (65.409). The molar volume $\left(V_{m}\right)$ of the glass samples has been calculated according to

$$
\begin{gathered}
V_{m}=\frac{M_{\text {glass }}}{\rho_{\text {glass }}}\left(\mathrm{cm}^{3}\right) \\
M_{\text {glass }}=\frac{\left\{(80-x) M_{\mathrm{TeO}_{2}}+20 M_{\mathrm{ZnO}}+(x) M_{\mathrm{Er}_{2} \mathrm{O}_{3}}\right\}}{(100)},
\end{gathered}
$$

where $M_{\text {glass }}$ and $\rho_{\text {glass }}$ are the mass and density of the glass sample, respectively. Molar volume of tellurite glass samples has been plotted in Figure 3. As the $\mathrm{Er}_{2} \mathrm{O}_{3}$ content in the EZT glasses increased, the density is also increased, hence

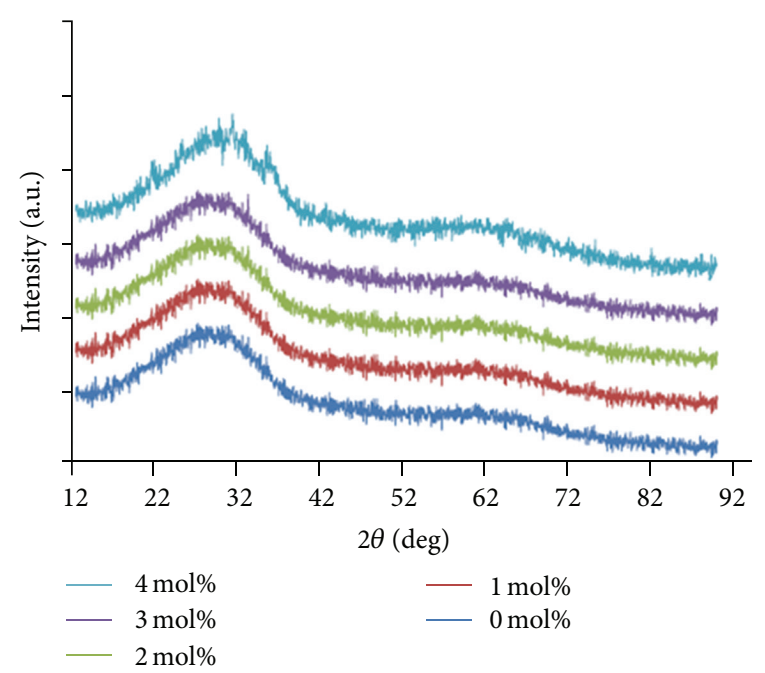

FIGURE 2: The XRD pattern of the EZT glasses.

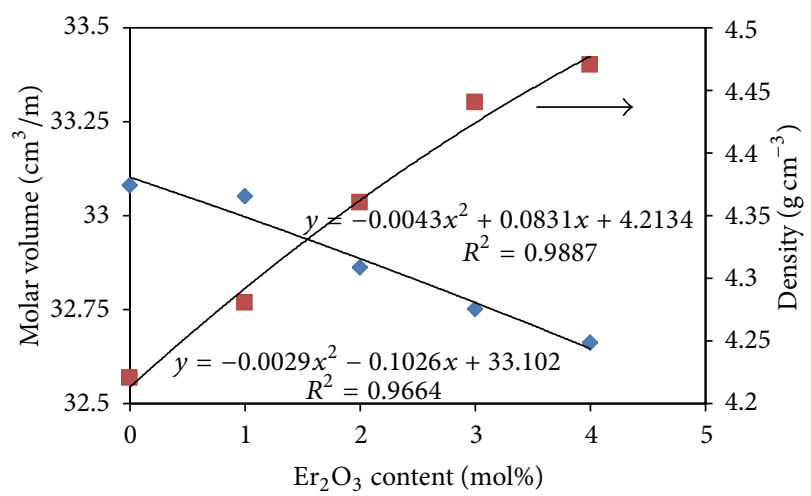

FIGURE 3: The variation of density and molar volume of EZT glass system.

resulting in the decrease of $V_{m}$. Based on the result obtained, the density and the molar volume of the EZT show an opposite trend. The increasing in density of the glasses is due to the heavier $\mathrm{Er}_{2} \mathrm{O}_{3}$ molecular mass compared to the other element in the glass system as shown in Table 1.

The UV-Vis-NIR absorption spectra for glass system ranging from 400 to $800 \mathrm{~nm}$ of wavelength are shown in Figure 4. It is found that optical absorption edge is not sharply defined in the present glasses, which clearly indicates their 


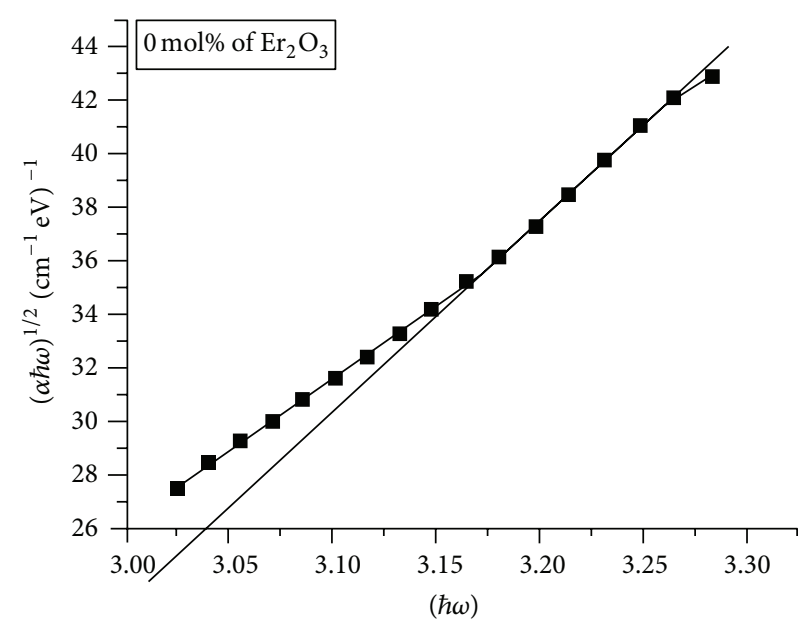

(a)

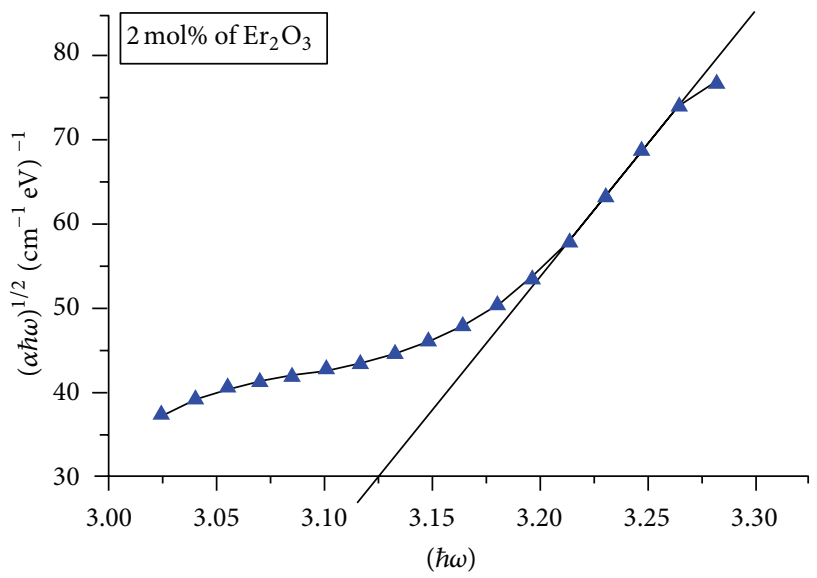

(c)

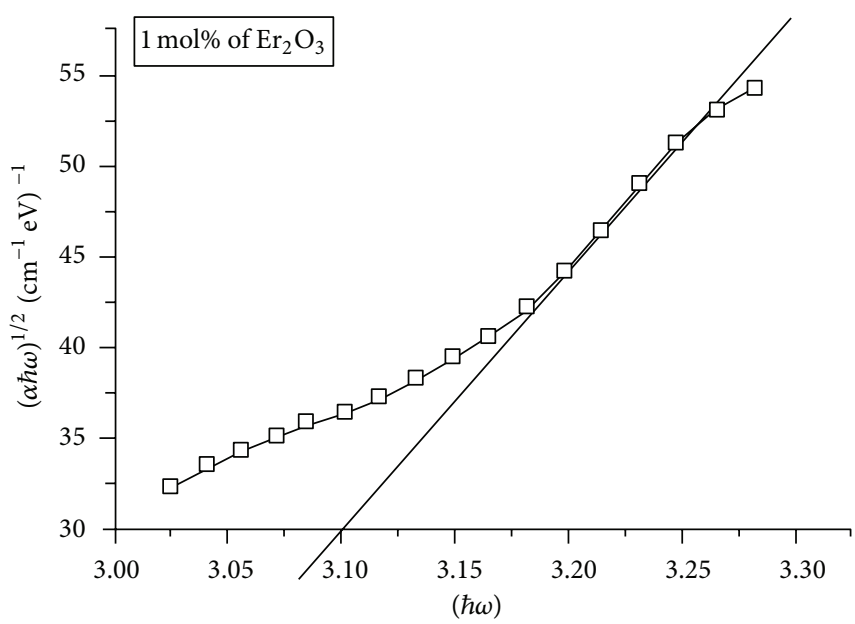

(b)

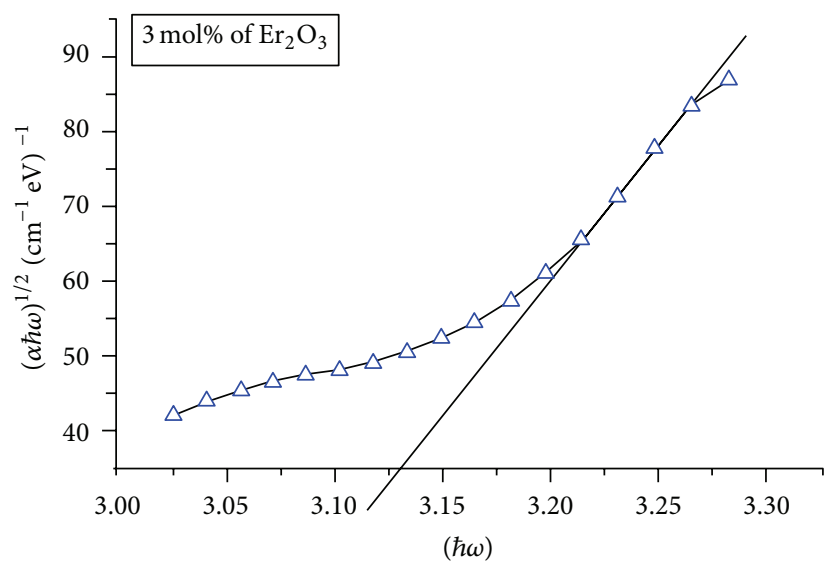

(d)

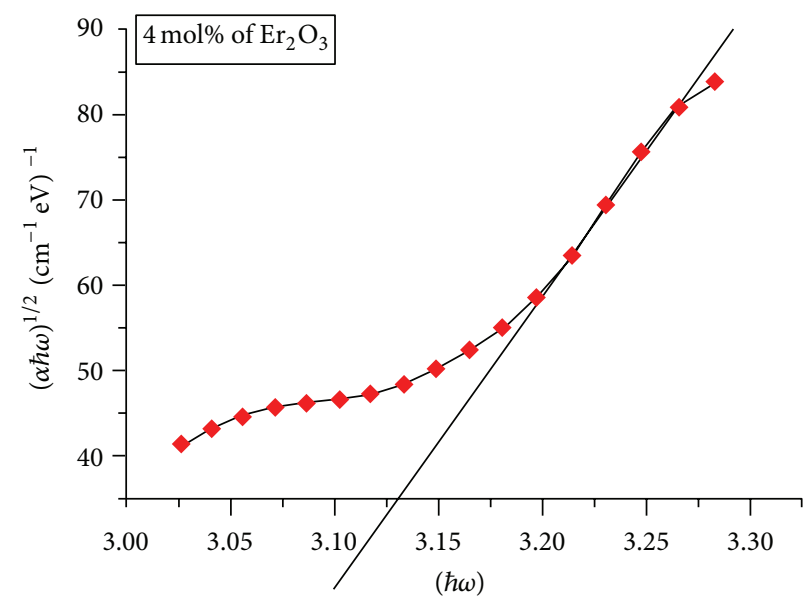

(e)

FIGURE 4: Graph of quantity $(\alpha \hbar \omega)^{1 / 2}$ against photon energy $(\hbar \omega)$ for $(80-x) \mathrm{TeO}_{2}-20 \mathrm{ZnO}-x \mathrm{Er}_{2} \mathrm{O}_{3}$ glasses. 


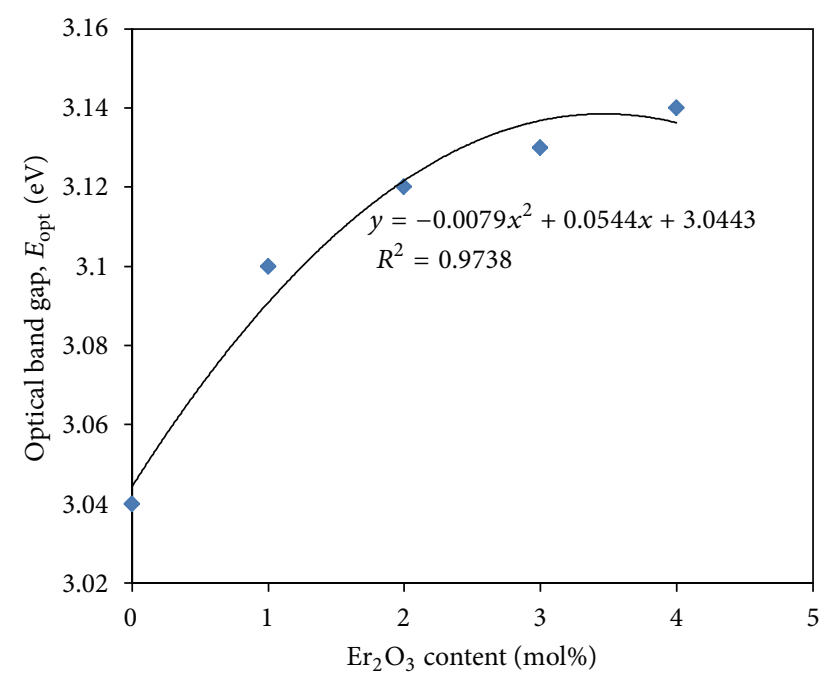

FIGURE 5: The nonlinear energy gap $E_{\text {opt }}$ variation in various $\mathrm{Er}_{2} \mathrm{O}_{3}$ content.

glassy nature. The optical band gap $E_{\text {opt }}$ values of the glasses can be calculated using the relation (proposed by Davis and Mott) between the absorption coefficient $\alpha(\omega)$ and photon energy $\hbar \omega$ of the incident radiation and are given below $[19,20]$ :

$$
\alpha(\omega)=\frac{A\left(\hbar \omega-E_{\mathrm{opt}}\right)^{n}}{(\hbar \omega)}
$$

where $E_{\text {opt }}$ is the optical band gap energy in $\mathrm{eV}, A$ is a constant, and the exponent $n$ takes different values depending on the mechanism of interband transitions [19]. The variation of the optical energy band gap $\left(E_{\text {opt }}\right)$ versus mol\% of $\mathrm{Er}_{2} \mathrm{O}_{3}$ is shown in Figure 5 where the optical band gap is gradually increased from 3.04 to $3.14 \mathrm{eV}$ as the $\mathrm{Er}_{2} \mathrm{O}_{3}$ content is added into the $\mathrm{ZnO}-\mathrm{TeO}_{2}$ glass system.

It should be noted however that the $E_{\text {opt }}$ is found to be higher than in a system with single doped $\mathrm{Er}_{2} \mathrm{O}_{3}$ (2.43$2.71 \mathrm{eV})[5]$ and lower than the pure $\mathrm{TeO}_{2}(3.97 \mathrm{eV})$. The observed increase of the optical band gap $E_{\text {opt }}$ is attributed to the substitution of $\mathrm{TeO}_{2}$ by $\mathrm{Er}_{2} \mathrm{O}_{3}$. The addition of small amount of rare-earth is capable of disturbing the disorder and consequently increases the optical band gap energy as shown in Table 1. Also, Figure 4 shows that several significant absorption peaks are observed which are contributed by the excited state of $\mathrm{Er}^{3+}$ ions.

The upconversion luminescence spectra in the range of $400 \mathrm{~nm}-650 \mathrm{~nm}$ at the excitation of $520 \mathrm{~nm}$ have been observed as shown in Figure 6. Some emission peak can be observed where the emission band center is around $555 \mathrm{~nm}$ to $557 \mathrm{~nm}$. It was clear that the higher mol\% of erbium doped into the glass gives the decrease of intensity. Usually, when the concentration is high, the nonradiative decay process will increase, while radiation relaxing decreases the intensity of luminescence decrease [21]. It was found that the higher mole $\%$ of erbium doped into the glass resulted in the decrease of the intensity due to the concentration of $\mathrm{Er}^{3+}$ that affected

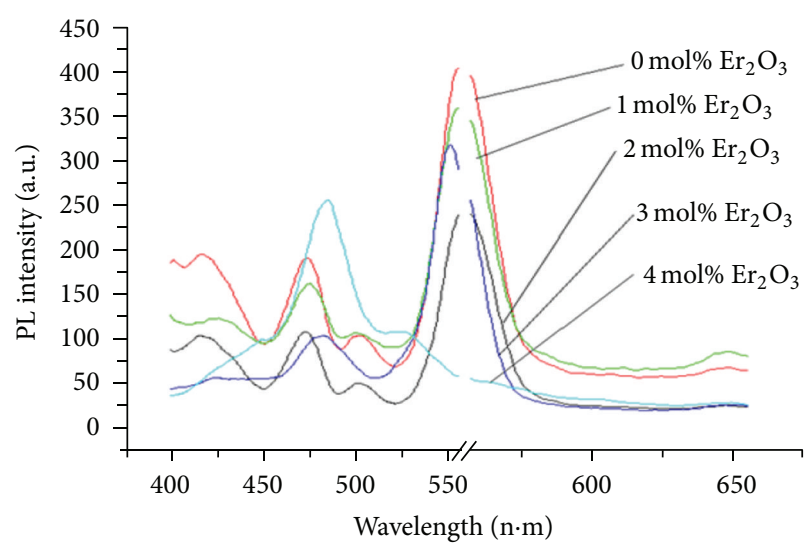

Figure 6: A luminescence spectrum of EZT glasses.

the intensity of upconversion luminescence [22]. The present data will be gathered with previous data on tellurite glass in order to study the structure of these glasses [23, 24].

\section{Conclusion}

New tellurite glasses in the form $x \mathrm{Er}_{2} \mathrm{O}_{3}-20 \mathrm{ZnO}-(80-$ $x) \mathrm{TeO}_{2}(x=0,1,2,3$, and 4 mole\%) (EZT) have been synthesized. The glasses have the following feature due to the increase of $\mathrm{Er}_{2} \mathrm{O}_{3}$ mol\%:

(1) density increased from 4.22 to $4.47 \mathrm{~g} / \mathrm{cm}^{3}$,

(2) molar volume decreased from 33.08 to $32.66 \mathrm{~cm}^{3}$,

(3) optical energy gap increased from 3.04 to $3.14 \mathrm{eV}$,

(4) upconversion luminescence spectra showed peaks at 555 to $557 \mathrm{~nm}$.

\section{Conflict of Interests}

The authors declare that there is no conflict of interests regarding the publication of this paper.

\section{Acknowledgments}

Part of this paper has been presented at the Fundamental Science Congress 2014, August 19-20, 2014, at Universiti Putra Malaysia, Serdang. The financial support from Ministry of Science, Technology and Innovation, Malaysia, and Universiti Putra Malaysia (UPM), each under the Fundamental Research Grant Scheme (vote no. 5524288) and Research University Grant Scheme (vote no. 9340800) is gratefully acknowledged.

\section{References}

[1] A. A. Assadi, K. Damak, R. Lachheb et al., "Spectroscopic and luminescence characteristics of erbium doped TNZL glass for lasing materials," Journal of Alloys and Compounds, vol. 620, pp. 129-136, 2015.

[2] F. Yang, C. Liu, D. Wei, Y. Chen, J. Lu, and S.-E. Yang, "Er ${ }^{3+}-\mathrm{Yb}^{3+}$ co-doped $\mathrm{TeO}_{2}-\mathrm{PbF}_{2}$ oxyhalide tellurite glasses for amorphous 
silicon solar cells," Optical Materials, vol. 36, no. 6, pp. 10401043, 2014.

[3] R. El-Mallawany, "Quantitative analysis of elastic moduli of tellurite glasses," Journal of Materials Research, vol. 5, no. 10, pp. 2218-2222, 1990.

[4] R. N. Hampton, W. Hong, G. A. Saunders, and R. A. El-Mallawany, "The dielectric properties of tellurite glass," Physics and Chemistry of Glasses, vol. 29, no. 3, pp. 100-105, 1988.

[5] R. El-Mallawany and I. A. Ahmed, "Thermal properties of multicomponent tellurite glass," Journal of Materials Science, vol. 43, no. 15, pp. 5131-5138, 2008.

[6] A. Abdel-Kader, R. El-Mallawany, and M. M. Elkholy, "Network structure of tellurite phosphate glasses: optical absorption and infrared spectra," Journal of Applied Physics, vol. 73, no. 1, pp. 71-74, 1993.

[7] R. El-Mallawany, "Structural and vibrational investigations of thermal properties of tellurite glasses," Journal of Materials Research, vol. 7, no. 1, pp. 224-228, 1992.

[8] M. M. El-Zaidia, A. A. Ammar, and R. A. El-Mallwany, "Infrared spectra, electron spin resonance spectra and density of $\left(\mathrm{TeO}_{2}\right)_{100-x}-\left(\mathrm{WO}_{3}\right)_{x}$ and $\left(\mathrm{TeO}_{2}\right)_{100-x}-\left(\mathrm{ZnCl}_{2}\right)_{x}$ Glasses," Physica Status Solidi (A) Applied Research, vol. 91, no. 2, pp. 637-642, 1985.

[9] I. Z. Hager, R. El-Mallawany, and M. Poulain, "Infrared and Raman spectra of new molybdenum and tungsten oxyfluoride glasses," Journal of Materials Science, vol. 34, no. 21, pp. 51635168, 1999.

[10] R. A. El-Mallawany and G. A. Saunders, "Elastic behaviour under pressure of the binary tellurite glasses $\mathrm{TeO}_{2}-\mathrm{ZnCl}_{2}$ and $\mathrm{TeO}_{2}-\mathrm{WO}_{3}$," Journal of Materials Science Letters, vol. 6, no. 4, pp. 443-446, 1987.

[11] R. N. Hampton, W. Hong, G. A. Saunders, and R. A. El-Mallawany, "The electrical conductivity of pure and binary $\mathrm{TeO}_{2}$ glasses," Journal of Non-Crystalline Solids, vol. 94, no. 3, pp. 307314, 1987.

[12] H. M. M. Moawad, H. Jain, R. El-Mallawany, T. Ramadan, and M. El-Sharbiny, "Electrical conductivity of silver vanadium tellurite glasses," Journal of the American Ceramic Society, vol. 85, no. 11, pp. 2655-2659, 2002.

[13] E. Culea, I. Vida-Simiti, G. Borodi, E. N. Culea, R. Stefan, and P. Pascuta, "Effects of $\mathrm{Er}^{3+}: \mathrm{Ag}$ codoping on structural and spectroscopic properties of lead tellurite glass ceramics," Ceramics International, vol. 40, no. 7, pp. 11001-11007, 2014.

[14] M. A. Sidkey, R. A. El-Mallawany, A. E.-S. M. Abousehly, and Y. B. Saddeek, "Elastic properties of tellurite glasses," Glass Science and Technology, vol. 75, no. 2, pp. 87-93, 2002.

[15] R. El-Mallawany, A. Abousehly, A. El-Rahamani, and E. Yousef, "Calorimetric study on tellurite glasses," Physica Status Solidi (A) Applied Research, vol. 163, no. 2, pp. 377-386, 1997.

[16] H. A. Sidek, R. El-Mallawany, K. Hariharan, and S. Rosmawati, "Effect of concurrent $\mathrm{ZnO}$ addition and AlF3 reduction on the elastic properties of tellurite based glass system," Advances in Condensed Matter Physics, vol. 2014, Article ID 174362, 7 pages, 2014.

[17] S. Zhao, "Spectroscopic properties of $\mathrm{Er}_{2} \mathrm{O}_{3}$-doped telllurite glass for $1.55 \mu \mathrm{m}$ optical amplifiers," Journal of Alloys and Compounds, vol. 424, pp. 243-246, 2005.

[18] M. K. Halimah, W. M. Daud, H. A. A. Sidek, A. W. Zaidan, and A. S. Zainal, "Optical properties of ternary tellurite glasses," Materials Science, vol. 28, no. 1, pp. 173-180, 2010.
[19] N. F. Mott and E. A. Davis, Electronic Processes in Non-Crystalline Materials, Clarendon Press, Oxford, UK, 1979.

[20] E. A. Davis and N. F. Mott, "Conduction in non-crystalline systems conductivity, optical absorption and photoconductivity in amorphous semiconductors," Philosophical Magazine, vol. 22, no. 179, pp. 903-922, 1970.

[21] F. Song, M. J. Myers, S. Jiang, Y. Feng, X. B. Chen, and G. Y. Zhang, "Effect of erbium concentration on upconversion luminescence of Er:Yb:phosphate glass excited by InGaAs laser diode," in 3rd Rare-Earth-Doped Materials and Devices, vol. 3622 of Proceedings of SPIE, pp. 182-188, International Society for Optics and Photonics, San Jose, Calif, USA, April 1999.

[22] R. El-Mallawany, A. Patra, C. S. Friend, R. Kapoor, and P. N. Prasad, "Study of luminescence properties of $\mathrm{Er}^{3+}$-ions in new tellurite glasses," Optical Materials, vol. 26, no. 3, pp. 267-270, 2004.

[23] R. El-Mallawany, "Evaluation of optical parameters of some tellurite glasses,” Optik, vol. 125, no. 20, pp. 6344-6346, 2014.

[24] N. Elkhoshkhany and R. El-Mallawany, "Optical and kinetics parameters of lithium boro-tellurite glasses," Ceramics International, vol. 41, no. 3, pp. 3561-3567, 2015. 

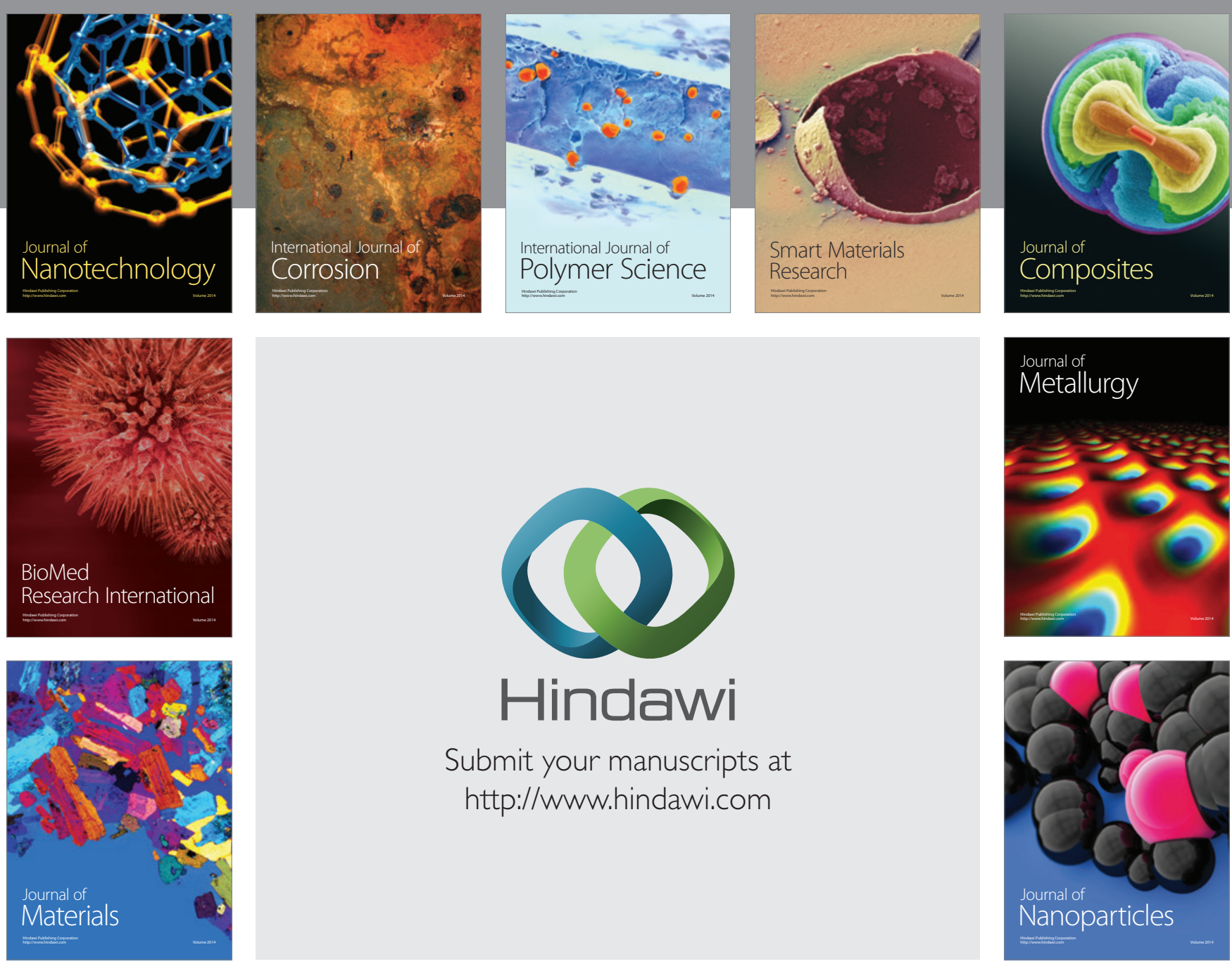

Submit your manuscripts at http://www.hindawi.com
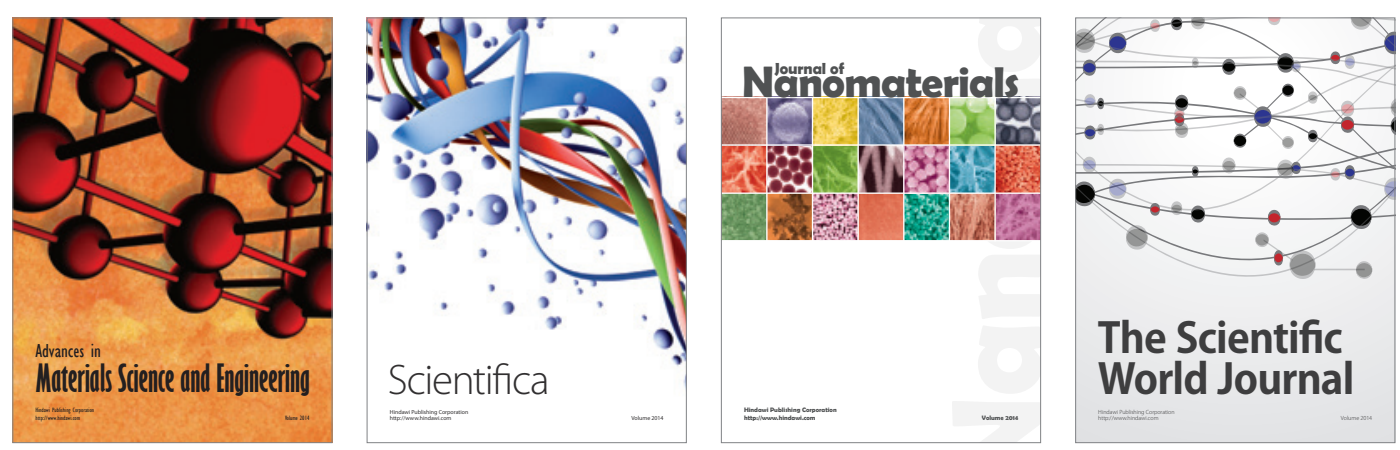

\section{The Scientific World Journal}
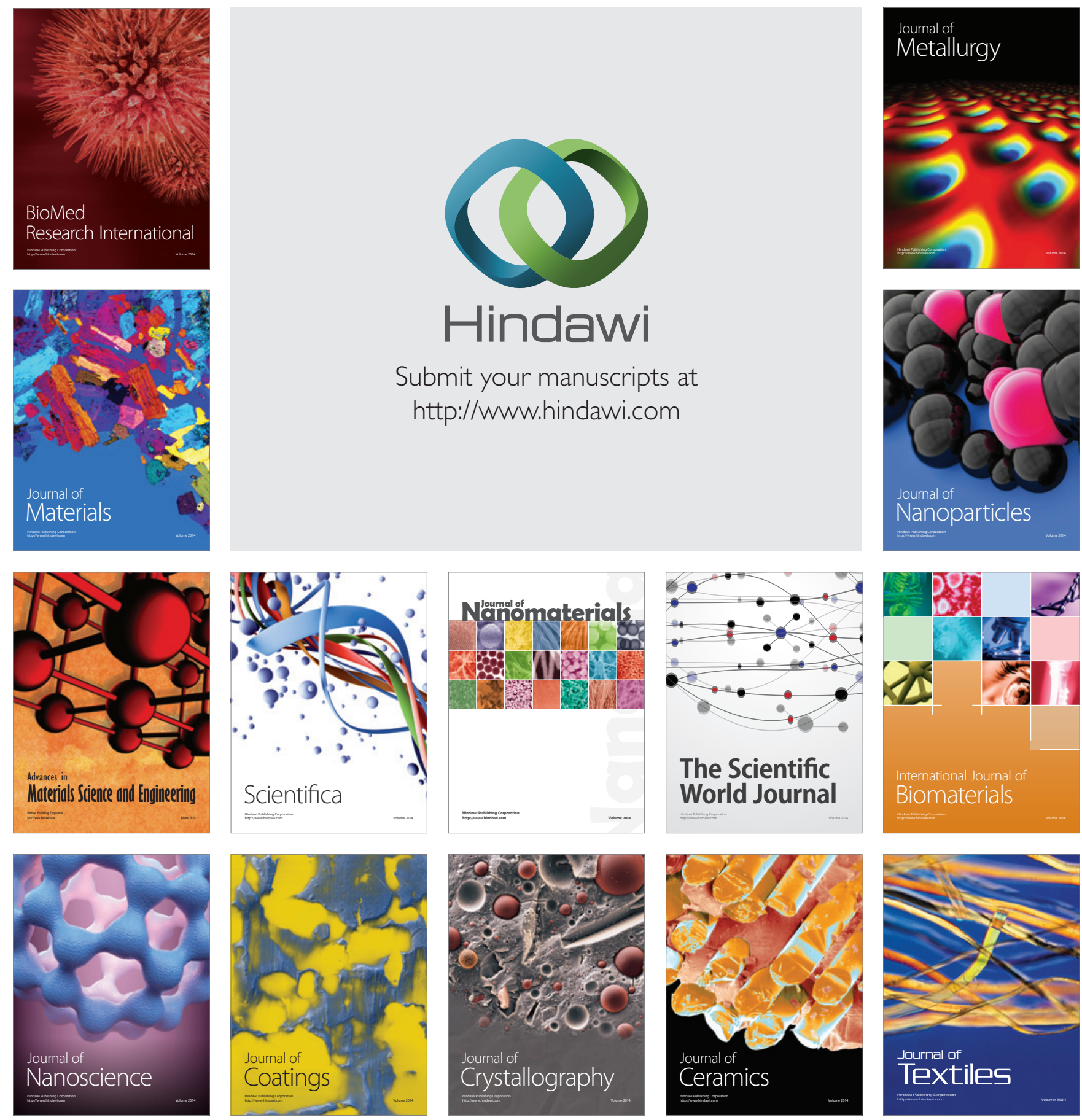